\title{
Neuromeningeal cryptococcosis in HIV-infected patients in Lubumbashi, Democratic Republic of the Congo
}

\begin{abstract}
Introduction: Neuromeningeal cryptococcosis (NMC) is a severe and fatal opportunistic infection. Lethality is higher in the absence of treatment, especially in HIV co-infection. The objective of the present study was to determine the prevalence, epidemiological, clinical, biological, and therapeutic features as well as the outcome of NMC in HIVinfected patients.
\end{abstract}

Methods: This is a retrospective study of 108 cases of NMC diagnosed in HIV-infected patients. Data were collected over 36 months (from January 2015 to December 2017) at the HIV/AIDS Center of Excellence in Lubumbashi (Democratic Republic of the Congo).

Results: The overall prevalence of NMC is $2.5 \%$. The mean age of the patients was $41.5 \pm 13.1$ years, with $72.2 \%$ aged less than 50 years. The main clinical symptomatology was headache $(100 \%)$ and fever $(100 \%)$. The main cytochemical CSF abnormalities were hyperproteinorachia (91.9\%), hypoglycorachia (94\%) and hyper-lymphocytosis $(98.2 \%)$. The mean CD4 count was $168.7 \pm 137.1 / \mathrm{mm}^{3}$. All patients were treated with fluconazole. The overall lethality was $43.5 \%$.

Conclusion: NMC is a serious opportunistic infection in HIV-infected patients, and the case fatality rate remains unacceptable. Management of NMC in HIV-positive patients requires early diagnosis, increased access to antiretrovirals and prompt initiation of appropriate treatment.

Keywords: neuromeningeal cryptococcosis, HIV-infected patients, mortality,
Volume II Issue 3 - 202I

\author{
Joe Kabongo Katabwa, ${ }^{1,2}$ Olivier Mukuku, ${ }^{3}$ \\ Guy Kanja Lwamba, ${ }^{2}$ Stanislas Okitotsho \\ Wembonyama 2,4 \\ 'Department of Internal Medicine, Faculty of Medicine, \\ University of Lubumbashi, Lubumbashi, Democratic Republic of \\ Congo \\ ${ }^{2}$ HIV / AIDS Center of Excellence of the University of \\ Lubumbashi, Lubumbashi, Democratic Republic of Congo \\ ${ }^{3}$ Institut Supérieur des Techniques Médicales, Lubumbashi, \\ Democratic Republic of Congo \\ ${ }^{4}$ Department of Pediatrics, Faculty of Medicine, University of \\ Lubumbashi, Lubumbashi, Democratic Republic of Congo
}

Correspondence: Dr Joe Kabongo Katabwa, Department of Internal Medicine, Faculty of Medicine, University of Lubumbashi, Lubumbashi, Democratic Republic of Congo, Email joekabongo2004@gmail.com

Received: May 04, 2020 | Published: May I4, 202 I Lubumbashi

Abbreviations: AIDS, acquired immunodeficiency syndrome; ART, antiretroviral therapy; CSF, cerebrospinal fluid; DRC: democratic republic of the congo; HIV, human immunodeficiency virus; NMC, neuromeningeal cryptococcosis

\section{Introduction}

Cryptococcus neoformans is a yeast (with a capsule that is a major virulence factor) which readily enters the body through the respiratory tract. Its localization is multisystem; however, this yeast has a marked tropism for the central nervous system, causing meningoencephalitis. It is a basidiomycete that is found in the environment, and its gateway into the body is the pulmonary airway. ${ }^{2}$ It is the infectious agent responsible for cryptococcosis. In immunocompetent people, infection is rare, but the advent of Acquired immunodeficiency syndrome (AIDS) has raised the incidence of this yeast infection in recent years. ${ }^{3}$ Neuromeningeal cryptococcosis (NMC) is one of the most common meningeal mycotic infections in human immunodeficiency virus (HIV). NMC has increased significantly in frequency since 1985 due to the increase in the number of cases diagnosed in patients infected with HIV, with the number of HIV-negative patients being stable. ${ }^{1}$ In Africa, it is currently one of the main major opportunistic infections that complicate HIV infection. ${ }^{2,3}$

NMC during HIV infection is a major problem in diagnosis and treatment. ${ }^{4,5}$ It is severe and fatal in the absence of treatment. ${ }^{6,7}$ Each year, the number of deaths worldwide is estimated at more than 400,000 deaths within three months of illness. ${ }^{3}$ In developed countries, cryptococcosis has not gone away and mortality in the first ten weeks varies between $10 \%$ and $25 \%$. $^{8,9}$

Antiretroviral therapy (ART) currently partially restores cellular immunity in HIV-infected patients. ${ }^{10,11}$ In addition, combinations of antifungals improve the prognosis of NMC. In low- and middleincome countries, mortality ranges from $60 \%$ to $70 \%{ }^{12-16}$

$\mathrm{NMC}$ is a therapeutic emergency. Its diagnosis requires a very expensive technical platform (culture of cerebrospinal fluid, brain imaging), compromised by socio-economic insecurity, infrastructure, the presence of several other infections, the lack of screening policy and the late access to health care. The lack of up-to-date epidemiological and clinical data on this fungal disease among HIV-infected patients in the Democratic Republic of the Congo (DRC) in general and specifically in Lubumbashi motivated this study. The present study set itself the objective of describing the epidemiological, clinical, biological, therapeutic, and outcome features of NMC in HIV-infected patients.

\section{Material and methods}

This is a retrospective study carried out on files of the patients received at the HIV / AIDS Center of Excellence of the University of Lubumbashi (CE-UNILU) at the Jason Sendwe hospital between January 2015 and December 2017. The patients' files selected and analyzed are those whose presence of a cerebrospinal fluid (CSF) examination report explicitly mentions the detection of $C$. neoformans, the cryptococcal antigen assay and positive HIV serology. 
Data were collected from medical records and parasitology laboratory registers. The diagnosis of NMC is established after studying the CSF. The identification was made thanks to the demonstration by direct microscopic examination after staining with India ink of encapsulated yeasts and the isolation of $C$. neoformans in culture on Sabouraud's medium with chloramphenicol (Biokar diagnostics). This yeast was identified using API1 20C identification galleries. The detection of cryptococcal antigens in the blood was carried out by latex test (Remel inc., United States). We excluded from this study all patients aged less than 15 years and all HIV-negative patients with NMC

For each patient, socio-demographic, clinical, biological, therapeutic, and outcome data were collected. These were analyzed using Epi Info software version 7.2.0.1.

\section{Results}

\section{Prevalence}

The files that were the subject of this study (positive HIV serology and NMC) numbered 108 among 4,283 patients, i.e. a prevalence of $2.5 \%$.

\section{Sociodemographic features}

The mean age of the patients was $41.5 \pm 13.1$ years (range: 15 and 70 years). The population under 50 years of age was predominant with $72.2 \%$ of the cases. The female sex was predominantly $54.6 \%$, or a sex ratio of 1.2 (Table 1).

Table I Distribution of 108 HIV-infected patients with Neuromeningeal cryptococcosis by age, sex and clinical signs

\begin{tabular}{|c|c|c|}
\hline Variable & $\begin{array}{l}\text { Number } \\
(n=108)\end{array}$ & Percentage \\
\hline \multicolumn{3}{|l|}{ Age } \\
\hline$<20$ years & 9 & 8.3 \\
\hline $20-29$ years & 8 & 7.4 \\
\hline $30-39$ years & 28 & 25.9 \\
\hline $40-49$ years & 33 & 30.5 \\
\hline $50-59$ years & 23 & 21.3 \\
\hline$\geq 60$ years & 7 & 6.5 \\
\hline \multicolumn{3}{|l|}{ Sex } \\
\hline Female & 59 & 54.6 \\
\hline Male & 49 & 45.4 \\
\hline \multicolumn{3}{|c|}{ Symptomatology } \\
\hline Fever & 108 & 100 \\
\hline Headache & 108 & 100 \\
\hline Neck Stiffness & 30 & 27.8 \\
\hline Motor deficit & 17 & 15.7 \\
\hline Balance disorder & 15 & 13.9 \\
\hline Consciousness & 12 & II.I \\
\hline Cough & 10 & 9.3 \\
\hline Seizures & 9 & 8.3 \\
\hline Vomitings & 9 & 8.3 \\
\hline
\end{tabular}

\section{Clinical features}

The mean time between the onset of symptoms and hospitalization was 12.22.4 days. The main clinical symptoms were in decreasing order of frequency (Table 2): headache (100\%), fever (100\%), neck stiffness $(27.8 \%)$, motor deficit (15.7\%), balance disorder (13.9\%), consciousness disorder $(11.1 \%)$, cough $(9.3 \%)$, convulsions $(8.3 \%)$, and vomiting $(8.3 \%)$. Toxoplasmosis was associated with NMC in $19.4 \%$ of cases $(21 / 108)$.

Table 2 Factors associated to death in HIV-infected patients with Neuromeningeal cryptococcosis

\begin{tabular}{|c|c|c|c|c|c|c|}
\hline Variable & $\begin{array}{l}\text { Total } \\
(\mathrm{N}=108)\end{array}$ & $\begin{array}{l}\text { Deceased } \\
(n=47)\end{array}$ & & $\begin{array}{l}\text { Survived } \\
(n=6 I)\end{array}$ & & p-value \\
\hline Age & & & & & & 0.818 \\
\hline$<40$ years & 45 & 19 & (42.2\%) & 26 & (57.8\%) & \\
\hline$\geq 40$ years & 63 & 28 & (44.4\%) & 35 & (55.6\%) & \\
\hline Sex & & & & & & 0.513 \\
\hline Female & 59 & 24 & (40.7\%) & 35 & (59.3\%) & \\
\hline Male & 49 & 23 & $(46.9 \%)$ & 26 & (53.1\%) & \\
\hline CD4 count & & & & & & 0.890 \\
\hline$<200$ cells $/ \mathrm{mm}^{3}$ & 72 & 31 & (43.1\%) & 41 & (56.9\%) & \\
\hline$\geq 200$ cells $/ \mathrm{mm}^{3}$ & 36 & 16 & (44.4\%) & 20 & (55.6\%) & \\
\hline \multicolumn{7}{|l|}{ Treatment-naive } \\
\hline $\begin{array}{l}\text { HIV-infected } \\
\text { patients }\end{array}$ & & & & & & 0.065 \\
\hline Yes & 70 & 35 & $(50.0 \%)$ & 35 & (50.0\%) & \\
\hline No & 38 & 12 & (31.6\%) & 26 & (68.4\%) & \\
\hline Toxoplasmosis & & & & & & 0.945 \\
\hline Absent & 87 & 38 & (43.7\%) & 49 & (56.3\%) & \\
\hline Present & 21 & 9 & (42.9\%) & 12 & (57.1\%) & \\
\hline
\end{tabular}

\section{Laboratory investigations}

In the CSF, cytochemical abnormalities observed were hyperproteinorachia $(91.9 \%)$, hypoglycorachia $(94 \%)$, and hyperlymphocytosis $(98.2 \%)$. Direct examination for cryptococcus after India ink staining was positive $72.7 \%$ of the time. The search for C. neoformans in CSF after culture on Sabouraud's medium supplemented with chloramphenicol was positive in all patients. Blood tests for cryptococcal antigens were positive in all patients ranging from $1 / 8$ to $1 / 128$. The mean CD4 T-lymphocytes were $168.7 \pm 137.1 \mathrm{cells} / \mathrm{mm}^{3}$ (range: 8 to 566 cells $/ \mathrm{mm}^{3}$ ). Sixty-six-point seven percent of the patients had a CD4 T-cell count below 200 cells $/ \mathrm{mm}^{3}$.

\section{Outcome}

The percentage of patients on ART was $35.2 \%$ and the mean duration of ART initiation was 13.8 \pm 12.3 months (range: 2 and 49 months). The initial treatment consisted of the monotherapy administration of fluconazole (for lack of amphotericin B on the market) as an infusion at a rate of $1200 \mathrm{mg}$ for 14 days divided into 3 daily doses of $400 \mathrm{mg}$ in all patients, with Relay with fluconazole 400 $\mathrm{mg} / 24 \mathrm{~h}$ per os for six weeks and $200 \mathrm{mg} / 24 \mathrm{~h}$ per os for secondary prophylaxis. The outcome was favorable in 61 patients, or in $56.5 \%$ of cases and fatal in 47 patients, or in $43.5 \%$ of cases. 
The lethality was higher in subjects aged $\geq 40$ years, males, with a CD4 count $\geq 200$ cells $/ \mathrm{mm}^{3}$, naïve to ART and without toxoplasmosis without significant difference $(\mathrm{p}>0.05)$.

\section{Discussion}

\section{Prevalence}

The hospital prevalence of NMC in HIV-infected patients is $2.5 \%$. Our rate is lower than those of studies carried out in other African countries ranging from $5.6 \%$ to $11.43 \%{ }^{17-21}$ Two Ivorian studies conducted by Kadjo et al. ${ }^{22,23}$ had noted a prevalence of 0.6 and $1.1 \%$. These authors found that in ten years, the frequency of this disease has almost halved. On the other hand, our prevalence is less than $1.4 \%$, $1.53 \%$ and $1.8 \%$ reported respectively by Dolo et al. ${ }^{24}$ and Chadli et al. ${ }^{25}$ in Morocco, and Bamba et al. ${ }^{26}$ in Burkina-Faso. These authors explain these low rates by the acceptable awareness of HIV infection in Morocco and access to triple antiretroviral therapy. A second reason for the low prevalence of NMC would be the low prevalence of HIV in the general population.

People living with HIV are at risk of developing various opportunistic infections, including fungal and bacterial infections. Late consultations make them susceptible to develop NMC. In addition, continued screening for this pathology in HIV-infected patients and associated factors is quite limited due to the lack of inexpensive screening and diagnostic tools. Added to this are the financial difficulties of patients because, since they take care of themselves, some of them die even before a diagnosis is made.

\section{Sociodemographic features}

The mean age of the patients is $41.5 \pm 13.1$ years and $72.2 \%$ of the patients were under 50 years old. This average age is slightly higher than that reported in other studies which find an average age of around 37 years. $^{21,23,25,27}$

In this study, NMC was more common in women (54.6\%) than in men $(45.4 \%)$. This feminization of the disease observed in our study corroborates with the results of African studies. ${ }^{21,23,28}$ The difference in prevalence between the two sexes could be caused due to the difference in exposure rather than the difference in susceptibility of host and environmental exposure, hormonal and genetic predisposition..$^{29,30}$

\section{Clinical features}

The mean time to symptomatology evolution of 12.2 days observed in our study is lower than that of other authors, in particular Kadjo et al. ${ }^{22}$ and Bissagnéné et al. ${ }^{12}$ and Millogo et al. ${ }^{31}$ which are 15.7 and 19 days respectively. It is higher than that of Kilani et al..$^{32}$ in Tunisia which is nine days, and also higher than that reported in European studies (where patients are well educated on HIV infection) which is less than a week. ${ }^{23}$

Clinical signs dominated by headache and fever noted in $100 \%$ of the cases is classic. ${ }^{20,24,26}$ In addition, headache (100\%), fever (100\%) and neck stiffness $(27.8 \%)$ are the most evocative symptomatic triad of the NMC in our patients. In a Moroccan study, headache was represented in $77 \%$, vomiting in $58 \%$, fever in $49 \%$ and stiff neck in $47 \% .{ }^{24}$ Other opportunistic infections have been associated with the NMC, including toxoplasmosis (19.4\%). Clinical signs are not specific, are multiple and their expression ranges from simple long-term fever to fulminant meningitis. This makes the clinical diagnosis of NMC problematic. ${ }^{19,20,23,26}$. Headache, fever, stiff neck and vomiting often dominate the symptomatology, most often onset. These signs require early management of immunocompromised patients.

\section{Laboratory investigations}

Biochemically and cytologically, CSF was specifically clear with moderate elevation of proteinorachia (91.9\%), hypoglycorachia (94\%), and hyper-lymphocytosis (98.2\%). These results of the CSF analysis corroborate those reported in patients from Casablanca (Morocco). ${ }^{25}$ Indeed, other studies have reported CSF abnormalities (hyperproteinorachia, hypoglycorachia and hyperlymphocytosis) in proportions of over $65 \% .^{23,24}$

In our patients, NJC occurred at a severe immunosuppression stage (CD4 $<200$ cells $/ \mathrm{mm} 3)$ in $66.7 \%$ of cases. These results are consistent with the data in the literature reporting high proportions of HIV-infected patients with severe immunosuppression. ${ }^{19,23}$ It would be useful to point out that in a severely immunosuppressed patient with a CD4 count below $200 / \mathrm{mm}^{3}$, any suspicion of meningitis should lead to a search for NMC.

\section{Outcomes}

From a therapeutic point of view, fluconazole as monotherapy because of its lower cost and its accessibility on the local market has been used in all of our patients. However, the treatment of choice for NMC is well codified, according to the recommendations of the Infectious Diseases Society of America. ${ }^{33}$ It is based on the combination of amphotericin B deoxycholate $(0.7$ to $1 \mathrm{mg} / \mathrm{kg} / \mathrm{day})$ and flucytosine $(100 \mathrm{mg} / \mathrm{kg} /$ day $)$ in the induction phase for two weeks followed by consolidation treatment with fluconazole at $400 \mathrm{mg}$ /day for 8 weeks. In sub-Saharan Africa and low- and middle-income countries in general, the accessibility and unavailability of antifungal molecules (liposomal amphotericin B and flucytosine) have limited the use of this therapy. The therapeutic alternative is based on high doses of fluconazole,$^{33}$ but the lethality of NMC remains high. Indeed, studies have clearly shown that the high dose would be more fungicidal (1200 mg vs. $800 \mathrm{mg}$ ) without any real impact on mortality. ${ }^{34,35}$.

NMC is known to be fatal in Africa. In our study, the lethality was $43.5 \%$. This lethality is greater than those reported in Kinshasa $(34.8 \%)^{19}$ and Bobo Dioulasso $(27.8 \%){ }^{26}$ but lower than those observed in other African series (from $71.1 \%$ to $83.3 \%$ ). ${ }^{32,36,37}$

These data clearly show the value of early management of patients with NMC. The improvement in the prognosis of NMC would be consecutive to a therapeutic success either of the viral infection or of the mycotic infection. In our study, there is an increase in the number of patients on ART. Widespread access to ART and the availability of drugs for opportunistic infections, provided by the budgets of the Ministry of Health and non-governmental organizations, have reportedly contributed to the decline in the prevalence of NMC and the reduction in case fatality.

Therapeutic success would also be due to early diagnosis. Late diagnosis is often linked to the complexity of the specific signs, but also to the resemblance of the initial clinical picture of malaria; which means that patients are treated with antimalarial drugs for a long time before being referred to our center for diagnosis and extemporaneous management. Added to this is the financial difficulties because the cost of care for opportunistic infections is in charge of the patient and his family. The diagnostic emergency requires the availability of the technical platform for the systemic search for cryptococcus in the CSF in HIV-infected patients admitted for neurological manifestations. 


\section{Conclusion}

Neuromeningeal cryptococcosis is a serious opportunistic mycosis, which occurs during the advanced stages of HIV immunosuppression. It remains a major concern in the era of triple therapy. It is characterized in our countries by a high lethality due to its late diagnosis. To fight against the NMC, reduce deaths and reduce the costs of health care, there was early in the absence of signs neuromeningeal detection and prompt initiation of appropriate treatment and prescribing effective systemic antifungal drugs is an effective strategy. Primary prevention is based on early diagnosis of HIV and initiation to ART with retention in care to avoid severe immunosuppression.

\section{Acknowledgments}

None.

\section{Conflicts of interest}

The authors declare no conflicts of interest.

\section{Funding}

None.

\section{References}

1. Numbi G, Mwad B, Mukuku O, et al. Cryptococcus neoformans meningitis in an immunocompetent adult: A case report. Advances in General Practice of Medicine. 2020;3(1):23-25.

2. Aberg JA, Powderly WG. Cryptococcosis and HIV. HIV in site know. Base chapter. New York: New York University; 2006.

3. Park BJ, Wannemuehler KA, Marston BJ, et al. Estimation of the current global burden of cryptococcal meningitis among persons living with HIV/AIDS. AIDS. 2009;23(4):525-530.

4. Gomerep SS, Idoko JA, Ladep NG, et al. Frequency of cryptococcal meningitis in HIV- 1 infected patients in north central Nigeria. Niger $J$ Med. 2010;19:395-399.

5. Gbangba-Ngai E, Fikouma V, Mossoro-Kpinde CD, et al. La cryptococcose neuroméningée au cours de l'infection à VIH à Bangui, à l'ère du traitement antirétroviral. Bull Soc Pathol Exot. 2014;107:106109.

6. Arechavala AI, Ochiuzzi ME, Borgnia MD, et al. Fluconazole and amphotericin B susceptibility testing of Cryptococcus neoformans: results of minimal inhibitory concentrations against 265 isolates from HIV-positive patients before and after two or more months of antifungal therapy. Rev Iberoam Micol. 2009;26(3):194-197.

7. Kammalac Ngouana T, Dongtsa J, Kouanfack C, et al. Cryptoccocal meningitis in Yaoundé (Cameroon) HIV infected patients: diagnosis, frequency and Cryptococcus neoformans isolates susceptibility study to fluconazole. J Mycologie Med. 2015;25(1):11-16.

8. Darras-Joly C, Chevret S, Wolff M, et al. Cryptococcus neoformans infection in France: epidemiologic features of early prognostic parameters for 76 patients who were infected with human immunodeficiency virus. Clin Infect Dis. 1996;23(2):369-376.

9. Dromer F, Mathoulin-Pélissier S, Launay O, et al. Determinants of disease presentation and outcome during cryptococcosis: the cryptoA/D study. PLoS Med. 2007;4(2):e21.

10. Dromer F, Mathoulin-Pelissier S, Fontanet A, et al. Epidemiology of HIV-associated cryptococcosis in France (1985-2001): comparison of the pre- and post-HAART eras. AIDS. 2004;18(3):555-562.
11. Jarvis JN, Harrison TS. HIV-associated cryptococcal meningitis. AIDS. 2007;21:2119-2129.

12. Bissagnéné E, Ouhon J, Kra O, et al. Current aspects of neuromeningitic cryptococcosis in abidjan. Med Mal Infect. 1994;24(Suppl 2):580-585.

13. Kambugu A, Meya DB, Rhein J, et al. Outcomes of cryptococcal meningitis in Uganda before and after the availability of highly active antiretroviral therapy. Clin Infect Dis. 2008;46(11):1694-1701.

14. Lawn SD, Harries AD, Anglaret X, et al. Early mortality among adults accessing antiretroviral treatment programmes in sub- Saharan Africa. AIDS. 2008;22:1897-1908.

15. Oumar AA, Dao S, Ba M, Poudiougou B, et al. Epidemiological, clinical and prognostic aspects of cryptococcal meningitis in hospital area of Bamako, Mali. Rev Med Brux. 2008;29(3):149-152.

16. Bicanic $\mathrm{T}$, Meintjes $\mathrm{G}$, Rebe $\mathrm{K}$, et al. Immune reconstitution inflammatory syndrome in HIV-associated cryptococcal meningitis: a prospective study. J Acquir Immune Defic Syndr. 2009;51(2):130-134.

17. Zait H, Arrache D, Madani K, et al. Vingt-quatre cas de cryptococcose diagnostiqués au laboratoire de parasitologie-mycologie du CHU Mustapha d'Alger (2002-2015). J Mycologie Med. 2015;25:237.

18. Kaouech E, Kallel K, Belhadj S, et al. Twenty-two cases of neuromeningeal cryptococcosis in Tunisia. Med Mal Infect. 2009;39(12):914-919.

19. Zono B, Kamangu E, Situakibanza H, et al. Epidemiological, clinical and biological profile of neuromeningeal cryptococcosis among people living with HIV in Kinshasa, Democratic Republic of Congo. The Pan African Medical Journal. 2020;37:302.

20. Seboxa T, Alemu S, Assefa A, et al Cryptococcal meningitis in patients with acquired immunodeficiency syndrome in prehaart era at Gondar College of Medical Sciences Hospital north-west Ethiopia. Ethiop Med J. 2010;48(3):237-241.

21. Jemal M, Deress T, Belachew T, Adem Y. Prevalence of Cryptococcal Antigenemia and Associated Factors among HIV/AIDS Patients at Felege-Hiwot Referral Hospital, Bahir Dar, Northwest Ethiopia. International Journal of Microbiology. 2021;2021:Article ID 8839238.

22. Kadjo K, Ouattara B, Kra O, et al. La cryptococcose neuroméningée à Abidjan. Med Afr Noire. 2007;54:66-68.

23. Kadjo K, Ouattara B, Adoubryn KD, et al. Current aspects of neuromeningeal cryptococcosis in adults infected with HIV in the internal medicine service of the University Hospital of Treichville Abidjan (Cote d'Ivoire). Journal de mycologie médicale. 2011;21(1):69.

24. Dollo I, Marih L, El Fane M, et al. Retrospective study of neuromeningeal cryptococcosis in patients infected with HIV in the infectious diseases unit of university hospital of Casablanca, Morocco. J Mycologie Med. 2016;26:331-336.

25. Chadli S, Aghrouch M, Malmoussi M, et al. Cryptococcose neuroméningée chez des patients infectés par le VIH au centre hospitalier régional d'Agadir (région Souss Massa, Maroc). Journal de Mycologie Médicale. 2017;27(3):e30.

26. Bamba S, Barro-Traoré F, Sawadogo E, et al. Retrospective study of cases of neuromeningeal cryptococcosis at the University Hospital of Bobo Dioulasso since accessibility to antiretroviral in Burkina Faso. $J$ Mycol Med. 2012;22(1):30-94

27. Azambuja AZD, Wissmann Neto G, Watte G, et al. Cryptococcal meningitis: a retrospective cohort of a Brazilian reference hospital in the post-HAART era of universal access. Canadian Journal of Infectious Diseases and Medical Microbiology. 2018;2018:Article ID 6512468.

28. Bitew A, Hassen M, Getachew T, et al. Prevalence of Crytpococcal infection in patients clinically diagnosed to have meningitis in Ethiopia. Clinical Medicine Research. 2016;5(4):73-76. 
29. Lindenberg ADSC, Chang MR, Paniago AMM, Lazéra MDS, Moncada PMF, Bonfim GF, et al. Clinical and epidemiological features of 123 cases of cryptococcosis in Mato Grosso do Sul, Brazil. Revista do Instituto de Medicina Tropical de São Paulo. 2008;50(2):75-78.

30. Kumar S, Wanchu A, Chakrabarti A, et al. Cryptococcal meningitis in HIV infected: Experience from a North Indian tertiary center. Neurology India. 2008;56(4):444.

31. Millogo A, Ki-zerbo GA, Andonaba JB, et al. La cryptococcose neuroméningée au cours de l'infection par le VIH au centre hospitalier de Bobo-Dioulasso (Burkina Faso). Bull Soc Path Exot. 2004;97:119121.

32. Kilani B, Ammari L, Marrakchi C, et al. Retrospective study of neuromeningeal cryptococcosis in aids patients in La Rabta hospital in Tunis (Tunisia). J Mycologie Med. 2005;15:114-115.

33. Perfect JR, Dismukes WE, Dromer F, et al. Clinical practice guidelines for the management of cryptococcal disease: 2010 update by the Infectious Diseases Society of America. Clinical infectious diseases. 2010;50(3):291-322.
34. Kouakou GA, Ello NF, Kassi NA, et al. Fluconazole $1200 \mathrm{mg}$ ou $800 \mathrm{mg}$ dans le traitement de la cryptococcose neuroméningée en Côte d'Ivoire. Journal de Mycologie Médicale. 2017;27(1):72-78.

35. Longley N, Jarvis JN, Meintjes G, et al. Cryptococcal antigen screening in patients initiating ART in South Africa: a prospective cohort study. Clinical Infectious Diseases. 2016;62(5):581-587.

36. Ouattara B, Eholié SP, Adoubryn KD, et al. Étude rétrospective des méningites bactériennes et à cryptococoques chez les sujets adultes infectés par le VIH à Abidjan (Cote d'Ivoire). J Mycol Med. 2007;17:8186.

37. Soumaré M, Seydi M, Ndour CT, et al. Aspects actuels de la cryptococcose neuroméningée à Dakar. Med Trop. 2005;65:559-562. 